\title{
Differential proteomic analysis of HL60 cells treated with secalonic acid $F$ reveals caspase 3 -induced cleavage of Rho GDP dissociation inhibitor 2
}

\author{
NING LI $^{1}$, ZHIWEI YI ${ }^{1}$, YUQIAO WANG ${ }^{1}$, QIN ZHANG $^{1}$, TIANHUA ZHONG ${ }^{1}$, \\ YINKUN QIU ${ }^{2}$, ZHEN WU ${ }^{2}$ and XIXIANG TANG ${ }^{1}$ \\ ${ }^{1}$ Key Laboratory of Marine Biogenetic Resources, Third Institute of Oceanography, \\ State Oceanic Administration; ${ }^{2}$ School of Pharmaceutical Sciences and Key Laboratory for \\ Chemical Biology of Fujian Province, Xiamen University, Xiamen 361005, P.R. China
}

Received March 15, 2012; Accepted June 8, 2012

DOI: 10.3892/or.2012.2062

\begin{abstract}
Secalonic acid F (SAF) has been previously identified, however, little is known about its cytotoxic activity and related cytotoxic mechanism. The aim of this study was to evaluate the cytotoxic activity of SAF isolated from a deep sea originated fungus Penicillium sp. F11 in HL60 cells and to analyze the differences in protein expression of HL60 cells treated with SAF. The CCK-8 assay and Annexin V-FLUOS/PI assay indicated that SAF displayed dose- and time-dependent inhibition of HL60 cell proliferation and induced apoptosis. Two-dimensional gel electrophoresis (2-DE) analysis of HL60 cells treated with SAF $(4 \mu \mathrm{g} /$ $\mathrm{ml})$ revealed 10 differentially expressed protein spots $(\mathrm{P}<0.05), 5$ upregulated and 5 downregulated. Three spots (1 downregulated and 2 upregulated) were identified as Rho GDP dissociation inhibitor 2 (RhoGDI 2) proteins by MALDI-TOF MS. Western blotting further demonstrated the decreased abundance of fulllength RhoGDI 2 together with the increased abundance of caspase 3-cleaved product of RhoGDI 2. The caspase 3 inhibitor Ac-DEVD-CHO could suppress the cytotoxic effect of SAF and significantly block the cleavage of RhoGDI 2. RhoGDI 2 is a cytosolic regulator of Rho GTPase and the caspase 3-cleaved product of RhoGDI 2 can advance progression of the apoptotic process. Our data showed that SAF may modulate RhoGDI 2 levels in HL60 cells, thereby potentially disrupting cell signaling pathways important for HL60 cell function.
\end{abstract}

\section{Introduction}

Due to the increasing incidence of malignant tumors year after year, identification of potential antitumor drugs from natural

Correspondence to: Dr Xixiang Tang, Key Laboratory of Marine Biogenetic Resources, Third Institute of Oceanography, State Oceanic Administration, Xiamen 361005, P.R. China

E-mail: tangxixiang@hotmail.com

Key words: secalonic acid F, Rho GDP dissociation inhibitor 2, cytotoxic activity, HL60 cell products has become more important. Marine environments, especially the deep sea surroundings, have their unique features, such as darkness, high salt, high pressure, low temperature and rare nutrition (1). Microorganisms living under those circumstances may develop unique metabolic pathways or defense mechanisms, which may relate to novel compounds with new structures and diverse bioactivity. Considering the incremental rediscovery of known compounds from terrestrial resources (2), more and more researchers have turned their attention to the marine environment for developing antitumor compounds (3). Gautschi et al (4) identified three compounds (anserinones A, B and (+)-formylanserinone B) from Penicillium corylophilum isolated from $1335 \mathrm{~m}$ deep sea sediments and those three compounds showed a good cytotoxic effect on the tumor cell line MDA-MB-435 (respective $\mathrm{IC}_{50}$ 2.2, 3.6 and $2.9 \mu \mathrm{g} / \mathrm{ml})$. Li et al (5) separated three antitumor compounds (oxosorbiquinol, dihydrooxosorbiquinol and trisorbicillinone A) from Phialocephala sp. FL30r isolated from $5059 \mathrm{~m}$ deep sea sediments. Du et al (6) characterized two new meleagrin analogs (meleagrin D and E) which showed weak cytotoxicity against A549 cell line from a deep ocean sediment derived fungus Penicillium sp.

Recently, we separated secalonic acid F (SAF) (Fig. 1) and two new compounds penicillone A and penicillactam from fungus Penicillium sp. F11 isolated from deep sea sediments at the depth of $1744 \mathrm{~m}$ in the Southwest Pacific (7). Unlike secalonic acid D (SAD), the isomeric compound of SAF, the cytotoxic activity and related mechanism of which have been studied (8-11), there is little information on the cytotoxic mechanism of SAF. In this study, cytotoxic effect evaluation and differential proteomic analysis of HL60 cells treated with SAF were conducted in order to preliminarily elucidate the mechanism of its cytotoxicity in HL60 cells.

\section{Materials and methods}

Chemicals and reagents. SAF was separated from the deep sea originated fungus Penicillium sp. F11. The HL60 cell line was purchased from the China Center for Type Culture Collection (CCTCC). The Cell Counting Kit-8 (CCK-8) was 
purchased from Dojindo Molecular Technologies (Japan). The Annexin V-FLUOS/PI staining kit was purchased from Roche Diagnostics GmbH (Germany). Anti-mouse RhoGDI 2 (3E6), anti-mouse RhoGDI 2 (2D7), anti-mouse $\beta$-actin (C4), peroxidase-conjugated secondary antibodies were purchased from Santa Cruz Biotechnology (USA). Anti-mouse caspase 3 antibody and the caspase 3 inhibitor Ac-DEVD-CHO were purchased from Beyotime Biotechnology (China).

$C C K-8$ assay. The cytotoxicity assay was carried out according to the instructions of the CCK-8 kit. Briefly, SAF at concentrations of $1.56,3.12,6.25,12.5$ or $25 \mu \mathrm{g} / \mathrm{ml}$ were added into the culture medium containing $105 / \mathrm{ml}$ HL60 cells and incubated for 24,48 and $72 \mathrm{~h}$. Then, $10 \mu \mathrm{l}$ of CCK-8 solution was added into each well of the 96-well plate, followed by incubation for $2 \mathrm{~h}$ and measurement of the absorbance at $450 \mathrm{~nm}$ using a microplate reader (Bio-Rad, USA). The inhibition rate was ( $A$ control $-A$ treated) $/ A$ control x 100 . The $\mathrm{IC}_{50}$ was taken as the concentration at which it caused $50 \%$ inhibition of cell proliferation $(50 \%$ reduction in the absorbance value in the treated cells, in respect to the control).

Annexin V-FLUOS/PI assay. The apoptosis rate was quantified by detecting the surface exposure of phosphatidyl-serine in apoptotic cells using the Annexin V-FLUOS/PI staining kit according to the manufacturer's instructions. Briefly, after being treated with $4 \mu \mathrm{g} / \mathrm{ml} \mathrm{SAF}$ for 24 and $48 \mathrm{~h}$, HL60 cells were collected and washed twice with cold PBS. Cells $\left(10^{6}\right)$ were resuspended with $100 \mu \mathrm{l}$ Annexin V-FLUOS labeling solution and incubated for $15 \mathrm{~min}$ at $25^{\circ} \mathrm{C}$ in the dark. The number of viable, apoptotic and necrotic cells were quantified by a flow cytometer (Becton-Dickinson, USA) and analysis by the CellQuest software. Around $10^{5}$ cells were analyzed for each sample. The apoptosis rate (\%) was calculated as (the number of apoptotic cells/the number of total cells observed) x $100 \%$.

Sample preparation for 2-DE. HL60 cells treated with $4 \mu \mathrm{g} / \mathrm{ml}$ SAF or DMSO as a control were harvested and washed three times with cold PBS. The washed cells were centrifuged at $1000 \mathrm{rpm}$ for $5 \mathrm{~min}$, then the pellet was treated with lysis buffer [9 mol/1 urea, $2 \mathrm{~mol} / \mathrm{l}$ thiourea, $4 \%$ (w/v) CHAPS, $50 \mathrm{mM}$ DTT, $5 \mathrm{mM}$ PMSF, 2\% ampholytes (pH 3-10)] and incubated at $37^{\circ} \mathrm{C}$ for $1 \mathrm{~h}$. After centrifugation at $50000 \mathrm{~g}$ for $30 \mathrm{~min}$, the supernatant was harvested and the protein concentration was determined by 2-D Quant Kit (Amersham Biosciences, USA). The protein lysate was stored at $-80^{\circ} \mathrm{C}$ until usage.

2-DE and image analysis. Protein samples $(200 \mu \mathrm{g})$ were mixed with rehydration buffer [7 mol/l urea, $2 \mathrm{~mol} / 1$ thiourea, 4\% (w/v) CHAPS, 0.2\% ampholytes (pH 3-10), 50 mM/1 DTT, and a trace of bromophenol blue]. IEF was carried out with $24 \mathrm{~cm}$ immobilized $\mathrm{pH}$ gradient strips ( $\mathrm{pH} 3-10$, non-linear gradient; Amersham Biosciences) in the IPGphor (Amersham Biosciences) for 58000 Volt-h. After focusing, strips were equilibrated in buffer A [50 mM/1 Tris- $\mathrm{HCl}(\mathrm{pH} 8.8), 6 \mathrm{~mol} / 1$ urea, 30\% (v/v) glycerol, 2\% (wt/v) SDS, $10 \mathrm{mg} / \mathrm{ml}$ DTT] for $15 \mathrm{~min}$, and then in buffer $\mathrm{B}[50 \mathrm{mM} / 1$ Tris- $\mathrm{HCl}(\mathrm{pH} 8.8)$, $6 \mathrm{~mol} / \mathrm{l}$ urea, 30\% (v/v) glycerol, $2 \%$ (w/v) SDS, $25 \mathrm{mg} / \mathrm{ml}$ iodoacetamide] for $15 \mathrm{~min}$. The second-dimension electro-

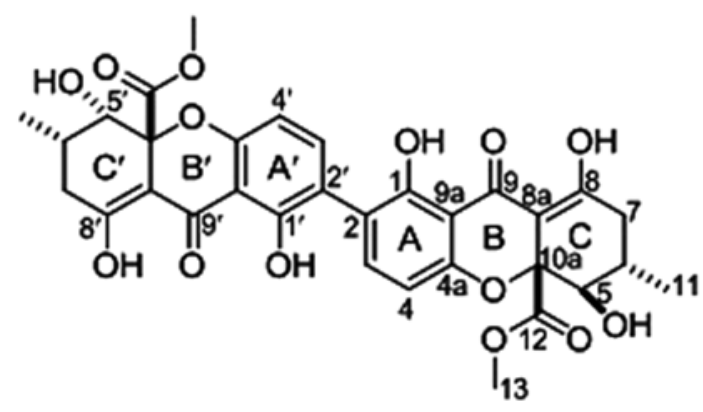

Figure 1. Structure of secalonic acid F.

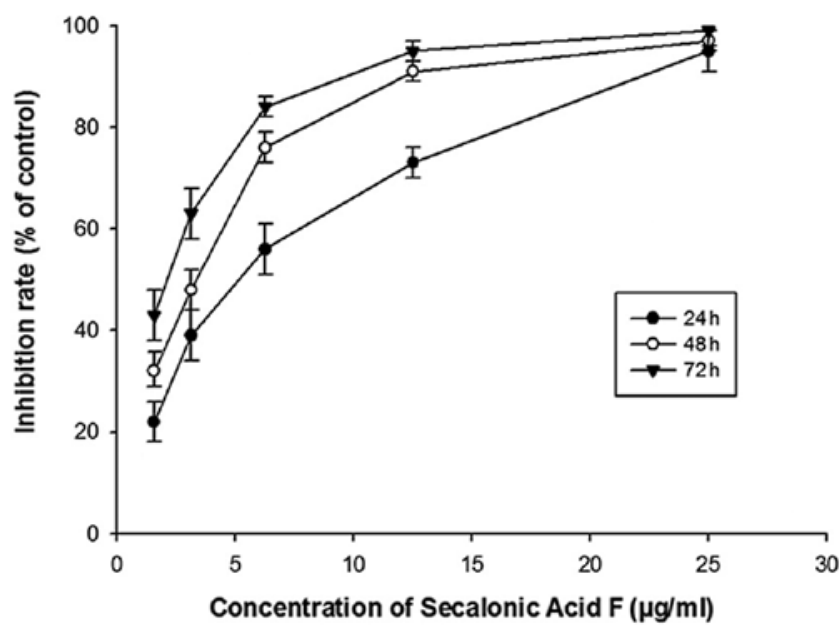

Figure 2. Inhibition effect of SAF on the proliferation of HL60 cells. The inhibition rate was measured by the CCK-8 kit. Data are shown as means \pm SD $(n=4)$. The results showed SAF could potently inhibit HL60 cells in a time and dose-dependent manner.

phoresis was carried out at a constant current of $15 \mathrm{~mA} / \mathrm{gel}$ for about $9 \mathrm{~h}$ using the Ettan ${ }^{\mathrm{TM}}$ DALTsix Electrophoresis Unit (Amersham Biosciences) and a MultiTemp III Thermostatic Circulator (Amersham Biosciences) at $25^{\circ} \mathrm{C}$ using the $12 \%$ polyacrylamide separation gel. Gels were then stained with a protein silver stain kit (Bio-Rad) according to the protocol. Gel image densitometric analysis was performed using the software PDQuest 8 (Bio-Rad). The intensity of each spot was normalized by total valid spot volume and reported as relative value (in ppm). Protein spots were detected automatically and then modified by manual operation. Only 2-fold differentially expressed spots with statistically significant differences $(\mathrm{P}<0.05)$ were chosen for further mass spectrometric analysis.

In-gel digestion and MALDI-TOF MS analysis. In-gel digestion and peptide extraction were performed as previously described (12). Protein spots were excised manually and destained at $50^{\circ} \mathrm{C}$ using $200 \mu \mathrm{l}$ destaining solution $(0.016 \mathrm{~g} / \mathrm{ml}$ sodium thiosulfate, $0.01 \mathrm{~g} / \mathrm{ml}$ potassium ferricyanide) and washed with water for three times. The gel pieces were dehydrated in $100 \%$ acetonitrile and dried in a vacuum centrifuge, then swollen in $3 \mu \mathrm{l}$ trypsin solution $(3 \mathrm{ng} / \mu \mathrm{l})$ and incubated at $50^{\circ} \mathrm{C}$ for $2 \mathrm{~h}$. The mass spectrum was performed on the MALDI-TOF-TOF 

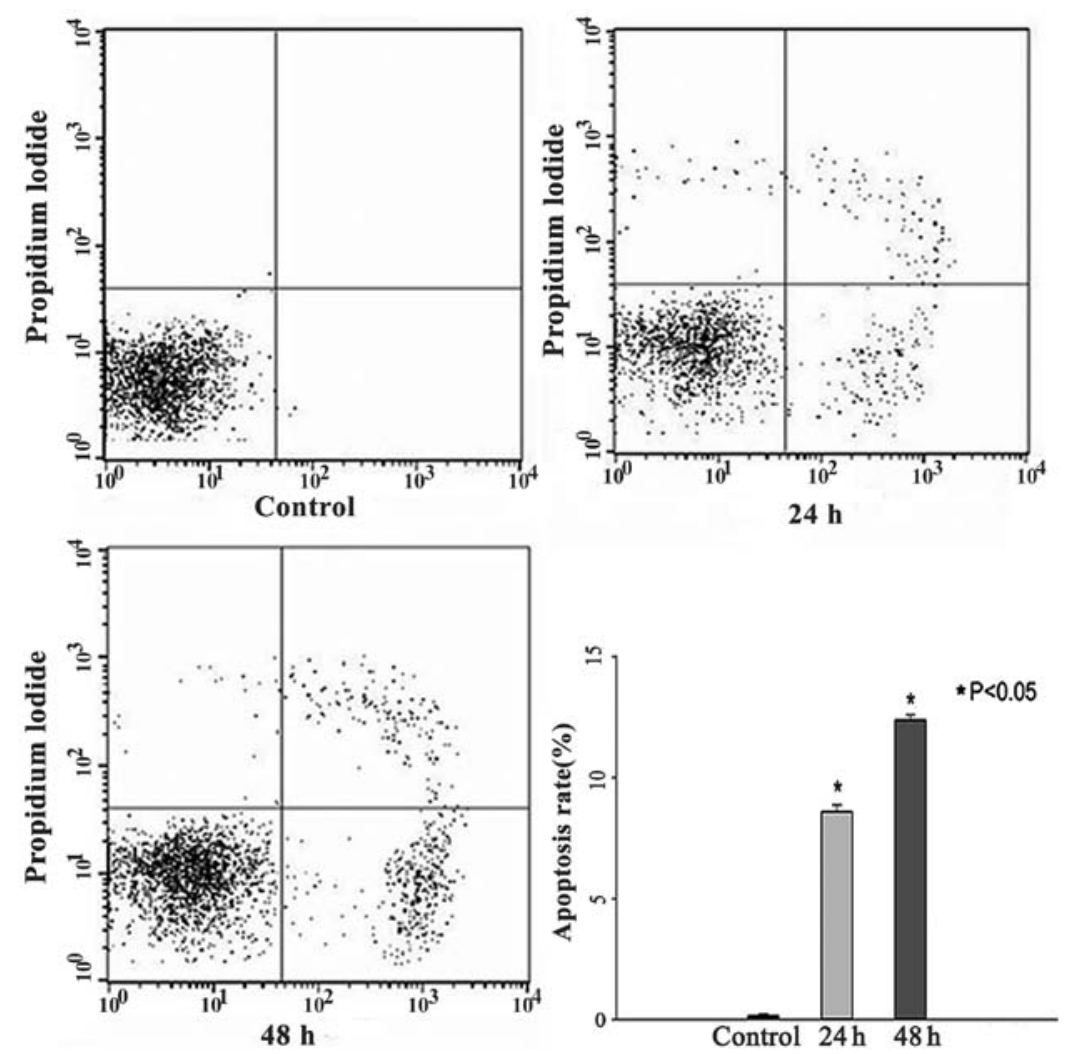

Figure 3. Cell apoptosis assay of HL60 cells mediated by SAF. Apoptosis were detected by Annexin V-FITC/PI double staining and flow cytometry. The down right quadrant represents early apoptotic cells stained mainly by Annexin V and the upper right quadrant stands for necrotic cells stained by both PI and Annexin V. The apoptosis rates are shown as means $\pm \mathrm{SD}(\mathrm{n}=3)$. The results indicate that $\mathrm{SAF}(4 \mu \mathrm{g} / \mathrm{ml})$ treatment for 24 or 48 h could significantly increase the apoptotic rate of HL60 cells $(\mathrm{P}<0.05)$.

5800 mass spectrometer (Applied Biosystems). Protein database searching was performed with the MASCOT search engine (http://www.matrix-science.com) using mono-isotopic peaks against the NCBI non-redundant protein database (12). Mass tolerance was allowed within $0.05 \%$. Proteins with the protein score CI $>95 \%$ were considered as credible results.

Western blot analysis. The basic methods of western blotting followed that of Towbin et al (13). Briefly, proteins were separated by electrophoresis on $12 \%$ polyacrylamide gels, transferred to PVDF membranes (Millipore, USA) and incubated with anti-mouse caspase 3, anti-mouse RhoGDI 2 (3E6), anti-mouse RhoGDI 2 (2D7) and anti-mouse $\beta$-actin (C4). After the antibodies reacted with the peroxidase-conjugated secondary antibody, results were visualized on Kodak films by using ECL plus reagents (Millipore).

Caspase 3 inhibitor assay. HL60 cells (10\%/well) were incubated in 96 -well plates overnight. The caspase 3 inhibitor Ac-DEVD-CHO $(20 \mu \mathrm{M})$ was added 30 min before SAF $(4 \mu \mathrm{g} /$ $\mathrm{ml}$ ) in a final volume of $100 \mu \mathrm{l}$ and incubated for different times $(12,24,36,48$ and $72 \mathrm{~h})$. HL60 cells treated with SAF (4 $\mu \mathrm{g} /$ $\mathrm{ml}$ ) only were used as control. Then the proliferation inhibition effects of HL60 cells were measured by the CCK-8 assay.

Statistical analysis. Statistical analysis was performed using the SigmaPlot version 10.0 for Windows (Systat Software) and statistical differences were determined using the Student's t-test. P-values $<0.05$ was considered as statistically significant. Data were presented as the mean \pm SD of at least triplicate determinations.

\section{Results}

SAF inhibited HL60 cell proliferation. The dose and time effects of SAF on HL60 cell proliferation were tested by the CCK-8 methods. The results indicated that along with the SAF concentration increasing, the inhibition rate gradually increased. Meanwhile, the inhibition rate of SAF in HL60 cells increased progressively with the incubation period extension at the same concentration (Fig. 2). The inhibitory effect of SAF $(5 \mu \mathrm{g} / \mathrm{ml})$ was apparent and achieved the $\sim 50 \%$ inhibition rate after 24-h treatment. SAF $(5 \mu \mathrm{g} / \mathrm{ml})$ incubation for 48 and $72 \mathrm{~h}$ resulted in inhibition rates of $\sim 70 \%$ and $\sim 90 \%$, respectively. The $50 \%$ inhibition concentration $\left(\mathrm{IC}_{50}\right)$ of SAF in HL60 cells was $4.1 \pm 0.16 \mu \mathrm{g} / \mathrm{ml}$ after incubation for $48 \mathrm{~h}$. Thus, $4 \mu \mathrm{g} / \mathrm{ml} \mathrm{SAF}$ was chosen for subsequent experiments.

SAF induced HL60 cell apoptosis. To clarify whether SAF induces cell apoptosis in HL60 cells, the cells were exposed to Annexin V-FLUOS and propidium iodide double staining and flow cytometry assay after treating with $4 \mu \mathrm{g} / \mathrm{ml} \mathrm{SAF}$ for 0,24 and $48 \mathrm{~h}$. The results showed that apoptosis rates were $0.15 \pm 0.08 \%, 8.58 \pm 0.29 \%$ and $12.37 \pm 0.22 \%$, respectively. (Fig. 3). The apoptosis rate was significantly increased in the 24 and $48 \mathrm{~h}$ groups $(\mathrm{P}<0.05)$. 

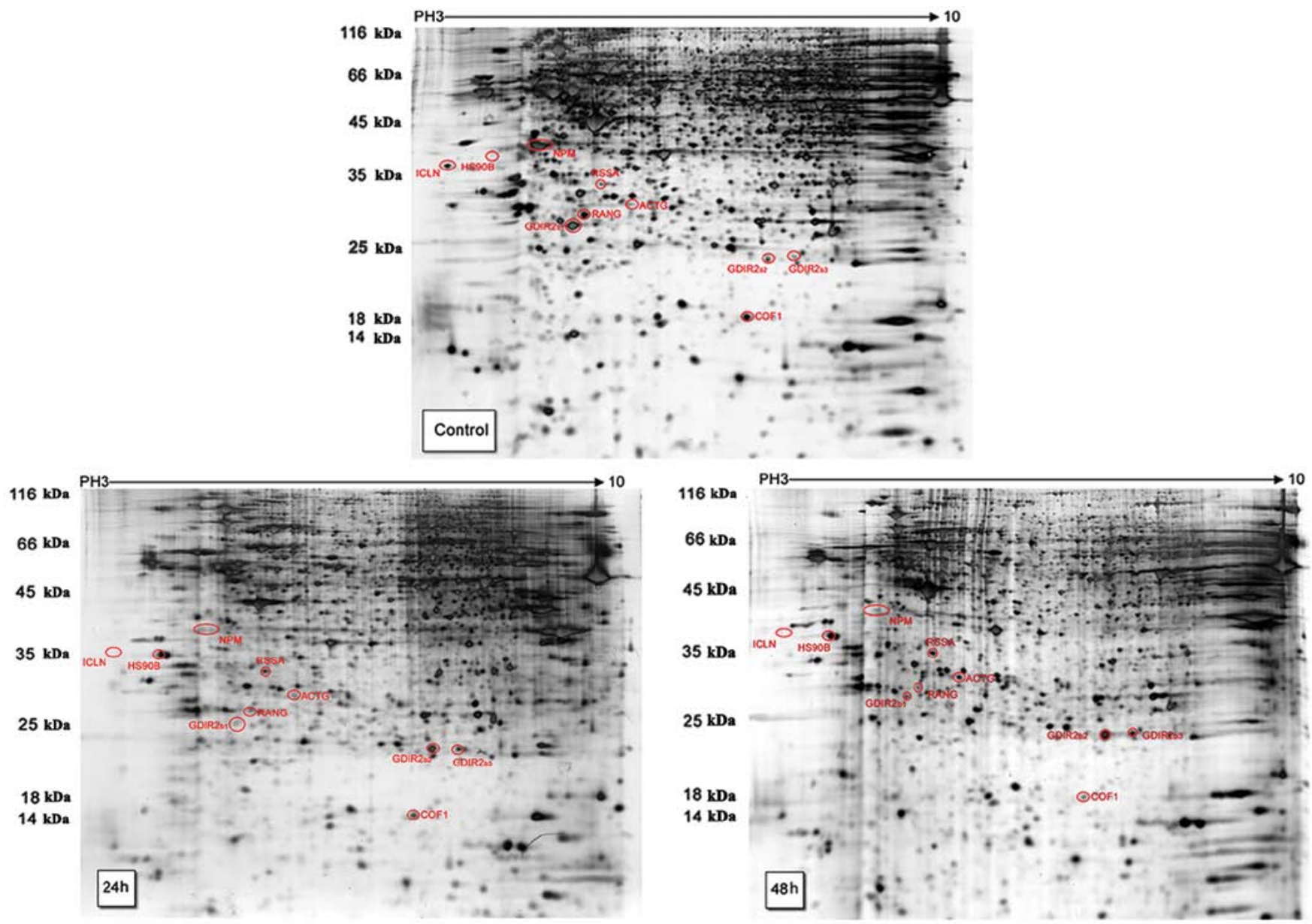

Figure 4. Representative 2-DE images (n=3). HL60 cells with adding DMSO as the control and SAF (4 $\mu \mathrm{g} / \mathrm{ml})$ for 24 and 48 h. Results showed about 1000 spots per image and the circled spots indicate differentially expressed proteins.

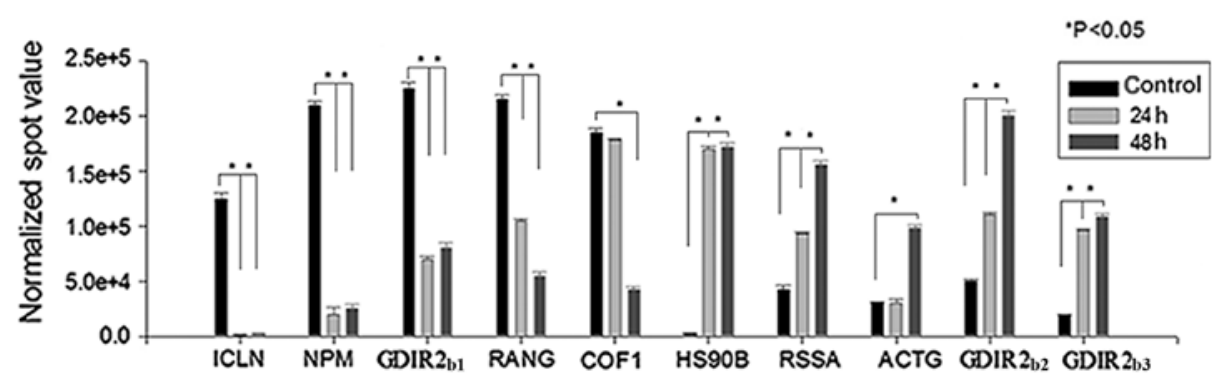

Figure 5. Ten differentially expressed proteins. Densitometric analysis results revealed ten significantly differentially expressed proteins including 5 upregulated and 5 downregulated $(\mathrm{P}<0.05)$ proteins.

SAF induced RhoGDI 2 differential expression by 2-DE and $M S$. The two-dimensional gels (Fig. 4) showed the separation of the about 1000 protein spots from HL60 cells. The 2-DE experiments were conducted in triplicate for the control (DMSO) and test groups by adding $4 \mu \mathrm{g} / \mathrm{ml} \mathrm{SAF}$ into HL60 cells for 24 and $48 \mathrm{~h}$. Through statistical analysis, the expression of 10 protein spots were found to be significantly changed (Fig. 5) and were identified by MALDI-TOF MS (Table I). The 5 downregulated spots were methylosome subunit (ICLN), nucleophosmin (NPM), RhoGDI 2 (GDIR $2_{\mathrm{b} 1}$ ), Ran-specific GTPase-activating protein (RANG) and cofilin-1 (COF1). The 5 upregulated spots were Hsp90 $\beta$ (HS90B), 40s ribo- somal protein SA (RSSA), actin cytoplasmic 2 (ACTG) and 2 RhoGDI 2 (GDIR $2_{\mathrm{b} 2}$, GDIR $_{2}$ ) $)$.

SAF induced caspase 3 activation and RhoGDI 2 cleavage by western blot analysis. Three spots were identified as RhoGDI 2 but only the spot $\left(\right.$ GDIR $\left.2_{b 1}\right)$ that displayed decreased abundance had a pI and apparent molecular weight consistent with the theoretical values for the native protein. The other two spots (GDIR $2_{\mathrm{b} 2}$, GDIR $2_{\mathrm{b} 3}$ ) that displayed increased abundance had higher $\mathrm{pI}$ values and lower molecular weights. To further characterize these three protein spots, western blotting was carried out using two different antibodies against RhoGDI 2, 
Table I. Details of the 10 differentially expressed proteins by MALDI-TOF MS.

\begin{tabular}{llccccc}
\hline & & & & & \multicolumn{2}{c}{ Change } \\
\cline { 5 - 7 } Protein & Abbreviation & Protein score & Accession no. & Mw (kDa)/PI & $24 \mathrm{~h}$ & $48 \mathrm{~h}$ \\
\hline Actin cytoplasmic 2 & ACTG & 218 & P63261 & $41.76 / 5.31$ & Unchanged & Up \\
40s ribosomal protein SA & RSSA & 366 & P08865 & $32.83 / 4.79$ & Up & Up \\
Hsp90- $\beta$ & HS90B & 352 & P08238 & $83.21 / 4.97$ & Up & Up \\
Rho GDP-dissociation inhibitor 2 & GDIR2 ${ }_{\mathrm{b} 2}$ & 223 & P52566 & $22.97 / 5.1$ & Up & Up \\
Rho GDP-dissociation inhibitor 2 & GDIR2 ${ }_{\mathrm{b} 3}$ & 145 & P52566 & $22.97 / 5.1$ & Up & Up \\
Methylosome subunit plcln & ICLN & 70 & P54105 & $26.19 / 3.97$ & Down & Down \\
Rho GDP-dissociation inhibitor 22 & GDIR2 $2_{\mathrm{b} 1}$ & 408 & P52566 & $22.97 / 5.1$ & Down & Down \\
Ran-specific GTPase-activating protein & RANG & 105 & P43487 & $23.29 / 5.19$ & Down & Down \\
Cofilin-1 & COF1 & 59 & P23528 & $18.49 / 8.22$ & Down & Down \\
Nucleophosmin B23 & NPM & 244 & P06748 & $32.55 / 4.64$ & Down & Down \\
\hline
\end{tabular}

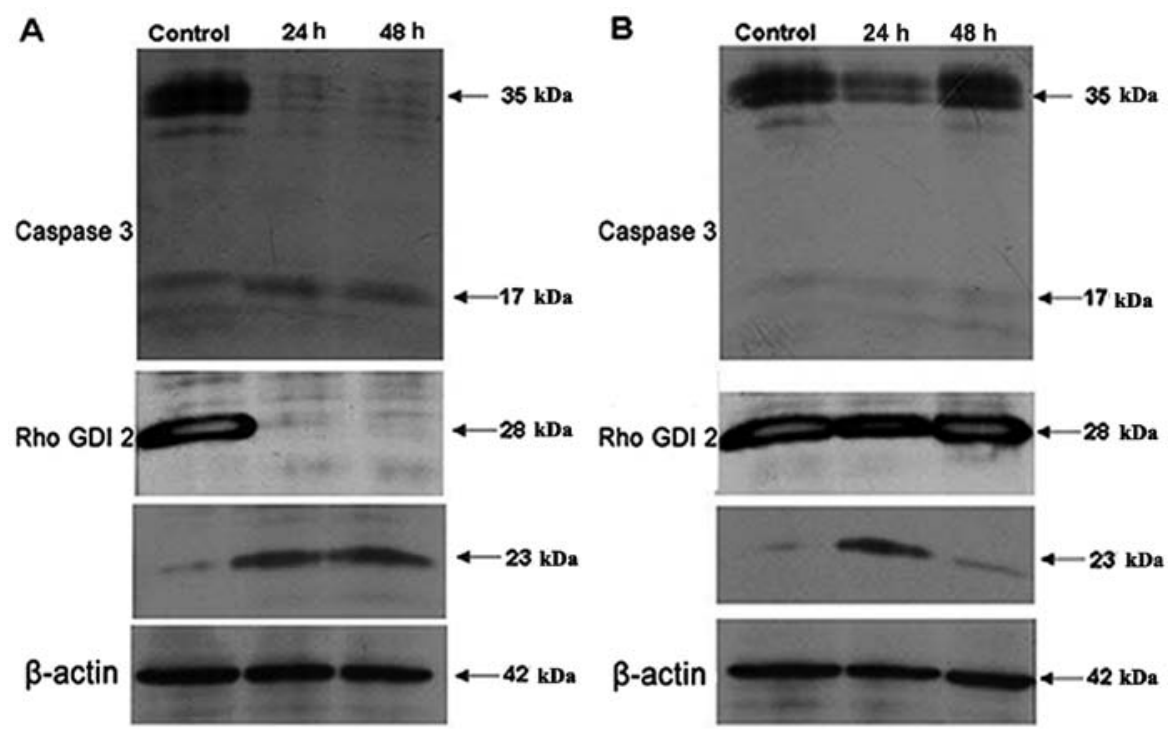

Figure 6. Validation of of RhoGDI 2 and caspase 3 in HL60 cells by western blotting. (A) RhoGDI 2 and caspase 3 expression in HL60 cells treated with SAF $(4 \mu \mathrm{g} / \mathrm{ml})$. (B) RhoGDI 2 and caspase 3 expression in HL60 cells treated with Ac-DEVD-CHO $(20 \mu \mathrm{M})$ for 30 min before SAF $(4 \mu \mathrm{g} / \mathrm{ml})$. $\beta$-actin was used as the reference. The results indicated that SAF could activate caspase 3 and result in the downregulated expression of full length RhoGDI 2 and upregulated expression of truncated RhoGDI 2, the caspase 3 cleavage product. Ac-DEVD-CHO pre-treatment could abolish this changing profile.

anti-mouse RhoGDI 2 (2D7) that recognizes full length RhoGDI 2 and anti-mouse RhoGDI 2 (3E6) that specifically recognizes the caspase 3 cleavage product of RhoGDI 2 . The results (Fig. 6A) showed that a band around $28 \mathrm{kDa}$ standing for the full length RhoGDI 2 downregulated while a band about $23 \mathrm{kDa}$ representing the caspase 3 cleaved products of RhoGDI 2 upregulated obviously after treating HL60 cells with $4 \mu \mathrm{g} / \mathrm{ml} \mathrm{SAF}$ for 24 and $48 \mathrm{~h}$. Caspase 3 was also activated during these processes.

Caspase 3 inhibitor Ac-DEVD-CHO reduced the proliferation inhibition effect induced by $S A F$. After the caspase 3 inhibitor Ac-DEVD-CHO $(20 \mu \mathrm{M})$ was added, the altered expression profile of caspase 3 and RhoGDI 2 was abolished (Fig. 6B). Also the caspase 3 inhibitor assay results showed that Ac-DEVD-CHO can significantly reduce SAF-induced HL60 cell proliferation inhibition at 24-72 h (Fig. 7).

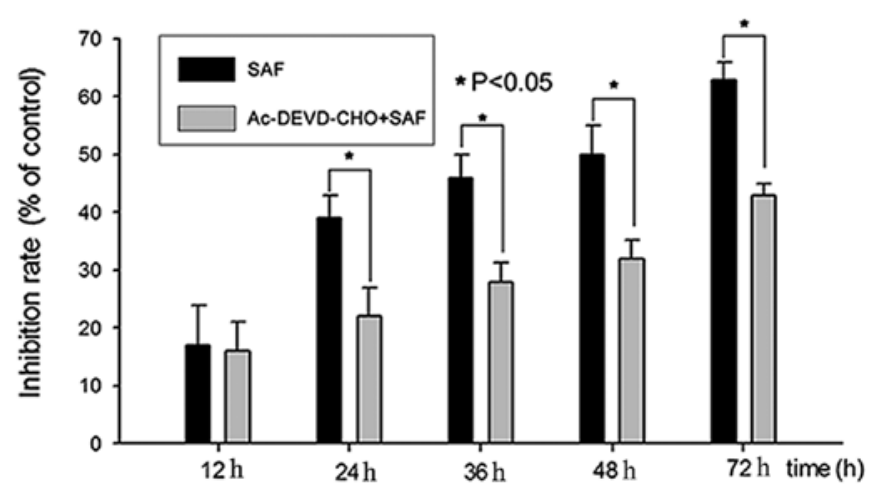

Figure 7. Ac-DEVD-CHO reduced growth inhibition effect of SAF on HL60 cells. The inhibition rate was measured by the CCK-8 kit. Data are shown as means $\pm \mathrm{SD}(\mathrm{n}=4)$. The results showed that the caspase 3 inhibitor Ac-DEVD-CHO could significantly reduce SAF-induced HL60 cell proliferation inhibition at $24-72 \mathrm{~h}(\mathrm{P}<0.05)$. 


\section{Discussion}

Malignant tumors are an increasing public health problem and are the number one cause of death in humans (14). Developing novel antitumor drugs is of great significance for tumor therapy. We found that SAF separated from the secondary metabolites of the deep sea originated fungus Penicillium sp. F11 showed potent antitumor activity. In this study, we conducted further investigations to elucidate the cytotoxic activity of SAF in HL60 cells and the possible mechanisms involved.

Our experimental data showed that SAF potently inhibited the proliferation of HL60 cells in a dose- and time-dependent manner and the half inhibitory concentration was calculated as $4.1 \pm 0.16 \mu \mathrm{g} / \mathrm{ml}$. Whether the cytotoxic activity is through apoptosis or necrosis was further tested by Annexin V-FLUOS/ PI assay and the results showed that SAF could induce HL60 cell apoptosis. Western blotting also indicated the activation of caspase 3, an important apoptosis-related protein after SAF treatment. To better understand the cytotoxicity related mechanism at the proteomic level, the 2-DE method was utilized and results revealed that caspase 3 induced cleavage of RhoGDI 2 in SAF-treated HL60 cells.

RhoGDI 2 (also named D4-GDI or Ly-GDI), belongs to the family of GDP dissociation inhibitors (GDIs) that include RhoGDI 1, RhoGDI 2 and RhoGDI 3. GDIs are cellular regulatory proteins which control the cellular distribution and activity of RhoGTPases (15-17). RhoGDI 2 is expressed preferentially in hematopoietic tissues and B- and T-lymphocyte cell lines (18) while RhoGDI 1 is expressed ubiquitously and RhoGDI 3 is expressed in the brain, lung, kidney, testis and pancreas (19). However, accumulating evidence indicates that RhoGDI 2 is aberrantly expressed in several human cancers and can function as a positive or negative regulator of cancer progression (20). Interruption of the RhoGDI 2-mediated cancer cell invasion and metastasis by an interfacial inhibitor may be a powerful therapeutic approach to cancer.

The N-terminus of RhoGDI 2 contains a cleavage site for caspase $3\left(\right.$ DELD $\left.^{19} \mathrm{~S}\right)$ and caspase $1\left(\operatorname{LLGD}^{55} \mathrm{G}\right)(21)$. Cleavage of RhoGDI 2 as a consequence of caspase 3 activation during apoptosis induced by drugs, like mycophenolic acid (22), daunorubicin (23), taxol and epirubicin (24) has been previously observed. In our research, three spots (1 downregulated and 2 upregulated) were also identified as RhoGDI 2 through 2-DE and western blotting verified that the full length RhoGDI 2 decreased in abundance and that the caspase 3 cleaved product of RhoGDI 2 decreased in abundance. The apparent shift in the isoelectric points of GDIR $2_{\mathrm{b} 1}(\mathrm{pI}=5.01)$ and its cleavage product GDIR $2_{\mathrm{b} 2}(\mathrm{pI}=6.78)$ is consistent with the loss of 9 acidic-amino acids from the N-terminus. Different degrees of phosphorylation of the two cleavage products GDIR $2_{\mathrm{b} 2}$ and GDIR $2_{\mathrm{b} 3}$ could provide a possible explanation for the slight differences in mobility (25).

RhoGDI 2 was cleaved in the cytoplasm and subsequently translocated to the nucleus (26). It has been reported (25) that overexpression of caspase 3 cleaved product of RhoGDI 2 in K562 cells could not affect cell proliferation but increased the sensitivity to apoptosis induction by PSI or staurosporine treatment. Nuclear export of the caspase 3 cleaved product of RhoGDI 2 abolished this apoptosis promoting property. We also blocked RhoGDI 2 cleavage through caspase 3 inhibitor assay, and the results indicated that SAF induced cell proliferation inhibition was significantly impaired. These experiments nevertheless suggested that the caspase 3 cleaved product of RhoGDI 2 could accelerate drug-induced apoptosis.

A previous study has shown that SAD (10), the isomeric compound of SAF, could induce apoptosis in HL60 cells by cell cycle arrest of the G1 phase related to downregulation of c-Myc which was demonstrated to be the result of the activation of GSK- $3 \beta$ followed by degradation of $\beta$-catenin. RhoGDI 2 was also expressed in HL60 cells treated with SAD $(1.2 \mu \mathrm{M})$ and the results of western blotting showed the same altered profile with SAF (data not shown). Based on our data, it is inferred that SAF and SAD could also promote the apoptosis procession through caspase 3 cleavage of RhoGDI 2.

In conclusion, SAF showed potent cytotoxicity and induced apoptosis in HL60 cells. Caspase 3-dependent RhoGDI 2 cleavage was also verified during SAF treatment. Although further studies are needed, our data shed some light on the activities and the cytotoxic mechanisms of SAF.

\section{Acknowledgements}

This study was supported by a Science and Technology project of Xiamen (3502Z20111051), the R\&D Special Fund for Public Welfare Industry (Oceanography) (201005022-1, 201005032-1) and the National Natural Science Foundation of China (81072549). We thank Professor Q.Q. Gu from Ocean University of China for providing secalonic acid D.

\section{References}

1. Yayanos AA: Microbiology to 10,500 meters in the deep sea. Annu Rev Microbiol 49: 777-805, 1995.

2. Zähner H and Fiedler HP: The need for new antibiotics: possible ways forward.In: Fifty Years of Antimicrobials: Past Perspectives and Future Trends. Hunter PA, Darby GK and Russell NJ (eds). Cambridge University Press, Cambridge, pp67-85, 1995.

3. Zhang L, An R, Wang J, et al: Exploring novel bioactive compounds from marine microbes. Curr Opin Microbiol 8: 276-281, 2005.

4. Gautschi JT, Amagata T, Amagata A, Valeriote FA, Mooberry SL and Crews P: Expanding the strategies in natural product studies of marine-derived fungi: a chemical investigation of Penicillium obtained from deep water sediment. J Nat Prod 67: 362-367, 2004.

5. Li D, Wang F, Cai S, et al: Two new bisorbicillinoids isolated from a deep-sea fungus, Phialocephala sp. FL30r. J Antibiot (Tokyo) 60: 317-320, 2007.

6. Du L, Feng T, Zhao B, et al: Alkaloids from a deep ocean sediment-derived fungus Penicillium $\mathrm{sp}$. and their antitumor activities. J Antibiot (Tokyo) 63: 165-170, 2010.

7. Zhuang P, Tang XX, Yi ZW, Qiu YK and Wu Z: Two new compounds from marine-derived fungus Penicillium sp. F11. J Asian Nat Prod Res 14: 197-203, 2012.

8. Hong R: Secalonic acid D as a novel DNA topoisomerase I inhibitor from marine lichen-derived fungus Gliocladium $\mathrm{sp}$. T31. Pharm Biol 49: 796-799, 2011.

9. Liao G, Zhou J, Wang H, et al: The cell toxicity effect of secalonic acid D on GH3 cells and the related mechanisms. Oncol Rep 23: 387-395, 2010.

10. Zhang JY, Tao LY, Liang YJ, et al: Secalonic acid D induced leukemia cell apoptosis and cell cycle arrest of $\mathrm{G}(1)$ with involvement of GSK-3 $\beta / \beta$-catenin/c-Myc pathway. Cell Cycle 8: 2444-2450, 2009.

11. Dhulipala VC, Maddali KK, Welshons WV and Reddy CS: Secalonic acid D blocks embryonic palatal mesenchymal cellcycle by altering the activity of CDK2 and the expression of p21 and cyclin E. Birth Defects Res B Dev Reprod Toxicol 74: 233-242, 2005. 
12. Asif AR, Armstrong VW, Voland A, Wieland E, Oellerich M and Shipkova M: Proteins identified as targets of the acyl glucuronide metabolite of mycophenolic acid in kidney tissue from mycophenolate mofetil treated rats. Biochimie 89: 393-402, 2007.

13. Towbin H, Staehelin T and Gordon J: Electrophoretic transfer of proteins from polyacrylamide gels to nitrocellulose sheets: procedure and some applications. Proc Natl Acad Sci USA 76: 4350-4354, 1979.

14. Jemal A, Bray F, Center MM, Ferlay J, Ward E and Forman D: Global cancer statistics. CA Cancer J Clin 61: 69-90, 2011.

15. Dovas A and Couchman JR: RhoGDI: multiple functions in the regulation of Rho family GTPase activities. Biochem J 390: 1-9, 2005.

16. DerMardirossian C and Bokoch GM: GDIs: central regulatory molecules in Rho GTPase activation. Trends Cell Biol 15 356-363, 2005.

17. Dransart E, Olofsson B and Cherfils J: RhoGDIs revisited: novel roles in Rho regulation. Traffic 6: 957-966, 2005.

18. Scherle P, Behrens T and Staudt LM: Ly-GDI, a GDP-dissociation inhibitor of the RhoA GTP-binding protein, is expressed preferentially in lymphocytes. Proc Natl Acad Sci USA 90: 7568-7572, 1993.

19. Sasaki T and Takai Y: The Rho small G protein family-Rho GDI system as a temporal and spatial determinant for cytoskeletal control. Biochem Biophys Res Commun 245: 641-645, 1998.
20. Cho HJ, Baek KE and Yoo J: RhoGDI2 as a therapeutic target in cancer. Expert Opin Ther Targets 14: 67-75, 2010.

21. Na S, Chuang TH, Cunningham A, et al: D4-GDI, a substrate of CPP32, is proteolyzed during Fas-induced apoptosis. J Biol Chem 271: 11209-11213, 1996.

22. Heller T, Asif AR, Petrova DT, et al: Differential proteomic analysis of lymphocytes treated with mycophenolic acid reveals caspase 3-induced cleavage of rho GDP dissociation inhibitor 2. Ther Drug Monit 31: 211-217, 2009.

23. Kwon KB, Park EK, Ryu DG and Park BH: D4-GDI is cleaved by caspase-3 during daunorubicin-induced apoptosis in HL-60 cells. Exp Mol Med 34: 32-37, 2002.

24. Essmann F, Wieder T, Otto A, Muller EC, Dorken B and Daniel PT: GDP dissociation inhibitor D4-GDI (Rho-GDI 2), but not the homologous rho-GDI 1, is cleaved by caspase-3 during drug-induced apoptosis. Biochem J 346 Pt 3: 777-783, 2000.

25. Choi MR, Groot M and Drexler HC: Functional implications of caspase-mediated RhoGDI2 processing during apoptosis of HL60 and K562 leukemia cells. Apoptosis 12: 2025-2035, 2007.

26. Krieser RJ and Eastman A: Cleavage and nuclear translocation of the caspase 3 substrate Rho GDP-dissociation inhibitor, D4-GDI, during apoptosis. Cell Death Differ 6: 412-419, 1999. 